\title{
Pentoxifylline effects on capacitation and fertility of stallion epididymal sperm
}

\author{
P.N. Guasti ${ }^{\text {a,* }}$, G.A. Monteiro ${ }^{\text {a }}$, R.R.D. Maziero ${ }^{a}$, M.T. Carmo ${ }^{a}$, J.A. Dell'Aqua Jr ${ }^{a}$, \\ A.M. Crespilho ${ }^{\text {b }}$, E.A. Rifai ${ }^{\mathrm{C}}$, F.O. Papa ${ }^{\mathrm{a}}$ \\ a Department of Animal Reproduction and Veterinary Radiology, School of Veterinary Medicine and Animal Science, São Paulo State \\ University, Botucatu, Brazil \\ b Santo Amaro University, São Paulo, Brazil \\ ' Division of Molecular E' Computational Toxicology, Vrije Universiteit Amsterdam, The Netherlands
}

\section{A R T I C L E I N F O}

\section{Article history:}

Received 5 September 2016

Received in revised form 15 January 2017

Accepted 29 January 2017

Available online 3 February 2017

\section{Keywords:}

Cauda epididymal sperm

Epididymis

Flushing extender

Tyrosine phosphorylation

Insemination dose

\begin{abstract}
A B S T R A C T
The aims of this study were to determinate whether pentoxifylline (PTX) increases the motion parameters of fresh and frozen-thawed equine epididymal spermatozoa, to evaluate the tyrosine phosphorylation of frozen-thawed epididymal sperm in the presence of PTX and to determine whether the PTX-treatment of stallion epididymal sperm prior to freezing improves the fertility response of mares to a reduced number of spermatozoa per insemination dose. Fifty epididymis were flushed with a skim milk based extender with or without PTX. The pre-treatment with PTX enhanced the sperm motility after being harvested $(P<0.05)$; however the freeze-thaw process did not alter the sperm kinematics between control and treated samples $(P>0.05)$. Plasma membrane integrity did not differ between control and PTX group after recovery and after thawing $(P>0.05)$, as observed in tyrosine phosphorylation, which the PTX treatment did not alter the percentage of tail-associated immunofluorescence of cryopreserved epididymal sperm $(P>0.05)$. For the fertility trial, different insemination groups were tested: $800 \times 10^{6}$ epididymal sperm (C800); $100 \times 10^{6}$ epididymal sperm (C100); $100 \times 10^{6}$ epididymal sperm recovered in an extender containing PTX (PTX100). The conception rates for C800; C100 and PTX100 were $68.7 \%(11 / 16) ; 31.5 \%(5 / 16)$ and $50 \%(8 / 16)$, respectively. The conception rate did not differ among groups $(P>0.05)$, however, a low number of animals was used in this study. A trend toward significance $(P=0.07)$ was observed between $C 800$ and $C 100$ groups. In conclusion, PTX has no deleterious effect on sperm motility, viability and capacitation of cryopreserved stallion epididymal sperm. The conventional artificial insemination with $100 \times 10^{6}$ sperm recovered with PTX ensures acceptable conception rates and maximize the limited number of doses of cryopreserved stallion epididymal sperm.
\end{abstract}

(c) 2017 Elsevier B.V. All rights reserved.

\footnotetext{
* Corresponding author at: Department of Animal Reproduction and Veterinary Radiology, Distrito de Rubião Júnior s/n, 18618-000 Botucatu, SP, Brazil.
}

E-mail address: priguasti@gmail.com (P.N. Guasti).

\section{Introduction}

The recovery of epididymal sperm might be the last chance to preserve the genetic material of endangered species or in case of unexpected injury of valuable sires, which will end their breeding career or cause death. Thus, many studies investigating different transportation and storage methods (Monteiro et al., 2013; Stawicky et al., 
2016), collection techniques (Cary et al., 2004; Bruemmer, 2006), flushing extenders (Papa et al., 2008; Guasti et al., 2013) have been performed in order to improve recovery and fertility rates of cauda epididymal sperm.

After collection, the epididymal sperm may remain immotile due to the quiescent state in the cauda epididymis (Turner and Reich, 1985). The quiescence has been reported in the rat, mouse, hamster (Morton et al., 1978) and bull spermatozoa (Cascieri et al., 1976) and may be dependent of some factors in the epididymal fluid e.g. proteins (Usselman and Cone, 1983), ions (Wong et al., 1983), pH (Acott and Carr, 1984) and cyclic AMP (Luconi et al., 2005).

Pentoxifylline (PTX) is a phosphodiesterase inhibitor of the methylxanthine group inhibiting the breakdown of cyclic adenosine monophosaphate (cAMP) (Tash, 1990). In sperm, cAMP has been shown to activate protein kinase (PKA) regulating protein tyrosine phosphorylation, which is an important regulatory pathway in modulating the events associated to capacitation (Naz and Rajesh, 2004). PTX is routinely used in assisted reproductive technology (ART) in humans (Carrel and Aston, 2013); in order to stimulate tail movements in immotile testicular spermatozoa and in ejaculated spermatozoa with very low motility sperm motility (Nassar et al., 1999) and it has been shown to improve the fertilization rates (Kovacic et al., 2006).

In equine-ejaculated spermatozoa, the presence of PTX enhances the quality of chilled and frozen semen (Goulart et al., 2004; Stephens et al., 2013). Therefore, the addition of PTX to epididymal sperm is assumed to improve the motility of the quiescent sperm cells and the fertility rate. However, in a previous study from our laboratory, treatment with equine epididymal sperm with PTX did not affect the post-thaw motility (Guasti et al., 2013).

The sperm-oocyte interaction depends on a series of events that occur in the female reproductive tract, which comprises the membrane-architectural and metabolic changes in spermatozoa (Yanagimachi, 1994). These maturational changes correspond to sperm capacitation, in which only capacitated sperm can bind to the zona pellucida (Gadella et al., 2001). The seminal plasma (SP) proteins are also described to be involved in sperm capacitation (Topfer-Petersen et al., 2005). The major stallion SP proteins (HSP-1 and HSP-2) are associated to sperm surface during ejaculation and their heparin-binding properties indicate a potential role in modulation of capacitation (Topfer-Petersen et al., 2005). However, the epididymal sperm is not exposed to seminal plasma and the capacitation process may be affected by the absence of these proteins.

The optimization of the use of cryopreserved epididymal sperm from a particular stallion is critical since only a limited amount of genetic material is available. Using a reduced number of spermatozoa per insemination may be an alternative to maximize the efficiency of this technique and to increase the fertility rate in the field. The hysteroscopic insemination of $150 \times 10^{6}$ fresh epididymal spermatozoa resulted in pregnancy rates per cycle of 45\% (Morris et al., 2002) and in the same study, higher pregnancy rates were obtained from hysteroscopic insemination $(9 / 51,18 \%)$ compared to the ones from conventional insemination $(1 / 13,8 \%)$ of $200 \times 10^{6}$ frozen-thawed epididymal spermatozoa. However, the hysteroscopic insemination requires expensive equipment and special-trained personnel, thus, is not readily available to the practitioner in the field. Therefore, strategies to improve the fertilizing ability and the optimization of stallion epididymal sperm should also be developed considering its applicability in the field through conventional artificial insemination.

The effect of pentoxifylline on capacitation and fertility of stallion epididymal spermatozoa has not been reported previously. The purpose of this study were: first, to determinate whether PTX increases the motion parameters of fresh and frozen-thawed equine epididymal spermatozoa; second, to evaluate the tyrosine phosphorylation of frozenthawed epididymal sperm in the presence of PTX; and third, to determine whether the PTX-treatment of stallion epididymal sperm prior to freezing improves the fertility response of mares to a reduced number of spermatozoa per insemination dose.

\section{Materials and methods}

\subsection{Animals}

A total of 25 stallions (experiment I and II: 23 stallions and experiment III: 2 stallions) between 3 and 5 years old were used. The fertility trial was conducted with 16 healthy mares between 4 and 15 years old with proven fertility. Experimental procedures were performed in accordance with the Institutional Ethics Committee of School of Veterinary Medicine and Animal Science (FMVZ), São Paulo State University (UNESP), concerning the protection of animals used in scientific experimentation.

\subsection{Orchiectomy}

Before castration, three ejaculates from each stallion were collected at 48-hr intervals to deplete epididymal sperm reserves. Then, after clinical exam, the stallions were submitted to bilateral orchiectomy using emasculator in standing position, under neuroleptic analgesia with $1 \%$ acepromazine $(0.04 \mathrm{mg} / \mathrm{kg})$ and after $15-20 \mathrm{~min} 10 \%$ xylazine $(0.5 \mathrm{mg} / \mathrm{kg})$, both intravenously (IV). The regional anesthesia was performed by injecting $10 \mathrm{~mL}$ of $2 \%$ lidocaine with epinephrine under the scrotal skin along the incision line using a 21-gauge 1.25 in. needle. An incision was made through the skin and fascia to expose the common vaginal tunic. The ligament of the epididymal cauda was detached, the testis was pushed dorsally, and the emasculator was positioned perpendicular to the spermatic cord and kept clamped for $2 \mathrm{~min}$. The testis was removed, cleaned with lactated ringer's solution (LRS) and the deferent duct was tied with a silk thread. The testis of each side was identified, placed in plastic bags containing $40 \mathrm{~mL}$ of LRS and stored in semen transport containers at $5{ }^{\circ} \mathrm{C}$ until arrival at the laboratory (approximately $5 \mathrm{~h}$ ).

After orchiectomy, tetanus (Lyophilized Anti-Tetanus Serum 5000 UI, Lema Injex Biologic, SP, Brazil) and antibiotic prophylaxis (benzilpenicilin benzatin 9,000,000 UI/per animal; Pentabiotic Veterinary Reinforced, Fort Dodge, SP, Brazil) were adopted. The horses were kept together in 
large pastures, the wound was cleaned and washed with flowing water for 4 days to reduce swelling and the animals were returned to exercise in 20 days after surgery.

\subsection{Collection and cryopreservation of cauda epididymal sperm}

The collection of the cauda epididymal sperm was performed using retrograde flushing. The epididymal cauda was isolated from the testis and the connective tissue and blood vessels were carefully removed. Epididymal sperm was recovered using a $10-\mathrm{mL}$ syringe attached to a $10-$ $\mathrm{mL}$ pipette tip positioned on top of the deferent duct and the flushed fluid was collected. One cauda epididymis from each stallion was flushed using a skim milk based extender (Control; BotuSemen Extender, Botupharma, Brazil) and the contralateral cauda epididymis was flushed with the same semen extender containing $7.18 \mathrm{mM}$ pentoxifylline (PTX; BotuTurbo Extender, Botupharma, Brazil).

After collection, the epididymal sperm samples were centrifuged at $600 \times g$ for $10 \mathrm{~min}$. The supernatant was discarded, and the sperm pellet was extended to a final concentration of $160 \times 10^{6}$ sperm/mL in an egg yolk freezing extender (BotuCrio, Botupharma, Brazil) and packaged into $0.5 \mathrm{~mL}$ straws. Then, the sperm samples were transferred to a refrigerator (Minitub; Porto Alegre, Brazil) and remained at a constant temperature of $5{ }^{\circ} \mathrm{C}$ for $20 \mathrm{~min}$. After cooling, an isothermal box of 42-L capacity was filled with a depth of $3.5 \mathrm{~cm}$ liquid nitrogen (N2) and the straws were placed horizontally at $6 \mathrm{~cm}$ above the level of $\mathrm{N} 2$ for $20 \mathrm{~min}$. Subsequently, straws were immersed into liquid nitrogen for storage (Papa et al., 2008).

\subsection{Sperm parameters}

\subsubsection{Experiment I. The effects of pentoxifylline on sperm parameters of fresh, centrifuged and frozen-thawed stallion epididymal spermatozoa}

The epididymal sperm samples were evaluated for sperm kinetics after recovery, after centrifugation and after thawing; and for plasma membrane integrity (PMI), samples were evaluated after collection and thawing. The straws were thawed at $46^{\circ} \mathrm{C}$ for $20 \mathrm{~s}$ (Dell'aqua and Papa, 2001), and the motility parameters were evaluated by computer assisted sperm analysis (CASA; HTM IVOS 12; Hamilton Thorne Research, USA). The computerassisted sperm analysis setup was similar as described by others (Guasti et al., 2013). The PMI was evaluated at $400 \times$ magnification by epifluorescence microscopy (Leica Microsystems, DMLB, Wetzlar, Germany) using the fluorescent probes carboxyfluorescein diacetate and propidium iodide as described by Harrison and Vickers (1990). A minimum of 200 sperm cells were examined per sample.

\subsection{Sperm capacitation}

\subsubsection{Experiment II. Determination of tyrosine} phosphorylation of cryopreserved equine epididymal sperm in the presence of pentoxifylline

The analysis of tyrosine phosphorylation was determined as described by Pommer et al. (2003). After being thawed at $46^{\circ} \mathrm{C}$ for $20 \mathrm{~s}$, a sperm suspension containing $20 \times 10^{6}$ cells were fixed in $2 \%$ paraformaldehyde, and then permeabilized with $0.1 \%$ Triton X-100 (Sigma-Aldrich, St Louis, USA) in Dulbecco phosphate buffered saline (DPBS). The samples were incubated in DPBS containing 5\% BSA, washed in DPBS and then incubated with anti-phosphotyrosine monoclonal antibody 4G10 (1:500; Upstate Biotechnology, Lake Placid, NY) or without the primary antibody (control) overnight at $48^{\circ} \mathrm{C}$. Samples were washed with DPBS and incubated with fluorescein-conjugated goat anti-mouse (Fab) IgG (1:350; Sigma-Aldrich, St Louis, USA) for $1 \mathrm{~h}$ at room temperature in the dark. The cells were washed in DPBS and a fluorescence enhancer was added (Vectashield, Vector, Burlingame, CA). Fluorescence was visualized using oil immersion at $1000 \times$ magnification with a fluorescence microscope (Leica Microsystems, DMLB, Wetzlar, Germany) using a fluorescein filter. Labeling patterns were determined of at least 100 cells per treatment.

\subsection{Fertility trial}

\subsubsection{Experiment III. Effect of pentoxifylline and} insemination dose on fertility of cryopreserved equine epididymal sperm

The epididymal samples of each group (control or PTX) were pooled to avoid individual stallion effects and frozen to a final concentration of $200 \times 10^{6}$ viable sperm $/ \mathrm{mL}$. The straws were thawed at $46^{\circ} \mathrm{C}$ for $20 \mathrm{~s}$ as previously described.

Forty-eight cycles from 16 mares (three cycles/mare) were used for inseminations and were randomly distributed among the following groups: $800 \times 10^{6}$ epididymal sperm recovered in a skim milk based extender ( $C$ 800); $100 \times 10^{6}$ epididymal sperm recovered in a skim milk based extender (C 100); $100 \times 10^{6}$ epididymal sperm recovered in a skim milk based extender containing pentoxifylline (PTX 100).

Mares were monitored daily by transrectal palpation and ultrasonography for estrus monitoring and uterine evaluation. When one follicle reached a diameter of $35 \mathrm{~mm}$ and uterine edema was detected, ovulation was synchronized with $1 \mathrm{mg}$ (intramuscular) of deslorelin acetate. Mares were monitored every $6 \mathrm{~h}$, starting $24 \mathrm{~h}$ after the induction of ovulation, until ovulation was detected. All inseminations were performed in the tip of the uterine horn, ipsilateral to the preovulatory follicle using a flexible pipette (Minitub; Porto Alegre, Brazil). Pregnancy diagnosis was performed by transrectal ultrasonography 14 days post-ovulation.

\subsection{Statistical analysis}

The sperm motility parameters, plasma membrane integrity and immunofluorescence assay were analyzed by univariate, repeated-measures analysis of variance using the General Linear Model (GLM) procedure of SAS Institute $^{\mathrm{TM}}$. Fisher's exact test was used to evaluate conception rates among insemination groups. The influence of the flushing extender and the insemination dose were analyzed by simple logistic regression using Proc Logistic 
9.1.3 computer program (SAS; SAS Institute Inc., Cary, NC, 1999). Data are presented as means \pm standard deviations. Differences were considered significant when $P<0.05$.

\section{Results}

\subsection{Experiment I}

Pre-freeze, centrifuged and post-thaw sperm motility parameters in control and PTX-treated sperm samples are compared in Table 1. After recovery, PTX treatment significantly increased the percentage of motile spermatozoa (TM), percentage of spermatozoa exhibiting progressive motility (PM), the average path velocity (VAP), the amplitude of lateral head displacement $(\mathrm{ALH})$ and the percentage of rapid spermatozoa $(P<0.05)$. However, after centrifugation, the PTX treatment only showed higher values for PM $(P<0.05)$. Moreover, sperm motility did not differ between control and treated samples $(P>0.05)$ after freezing-thawing. Considering the PTX treatment separately, no difference was found in TM and RAP after recovery and after thawing $(P>0.05$; Table 1$)$.

Plasma membrane integrity did not differ between control and treated group after recovery and after thawing $(P>0.05)$. However, the freeze-thaw process significantly decreased the percentages of live sperm in both control and PTX group $(P<0.05$; Table 1$)$.

\subsection{Experiment II}

The immunofluorescent labeling patterns and analysis of equine epididymal sperm were the same as described by Pommer et al., 2003. Four types of labeling patterns were identified: (a) equatorial band, (b) tail, (c) equatorial band with tail, and (d) none (Fig. 1). For immunofluorescence analysis, tail and equatorial band with sperm tail labeling (patterns b and c) were combined and classified as "tail" (capacitated) while equatorial band and none labeling (patterns a and d) were combined and classified as "other" (non-capacitated). Immunofluorescence labeling indicated that, the presence of PTX in flushing extender did not alter the percentage of other and tail-associated immunofluorescence of cryopreserved epididymal sperm $(P>0.05$; Fig. 2).

\subsection{Experiment III}

The conception rate did not differ significantly among groups $(P>0.05$; Table 2$)$; however, a trend toward significance $(P=0.07)$ was observed between the conception rates of mares inseminated with $800 \times 10^{6}$ (C 800) and $100 \times 10^{6}$ control epididymal sperm (C 100).

A significant effect of the insemination dose on conception rates was observed $(P=0.0387)$; however, the treatment did not influence conception rates $(P=0.2837)$.

\section{Discussion}

The use of a flushing extender containing PTX was effective to induce sperm motility of recently recovered stallion cauda epididymal sperm, as demonstrated in human, mouse and domestic cat epididymal sperm (Stachecki et al., 1994; Terriou et al., 2000; Rashidi et al., 2004). After recovery, the PTX did not only increase the number of motile sperm but also improved sperm motility parameters, as average path velocity and amplitude of lateral head displacement. On the other hand, it has also been reported that PTX does not increase the number of motile sperm or may be deleterious to sperm motility (Lewis et al., 1994; Gil et al., 2010; Hassanpour et al., 2010). These differences may be related to the origin of the samples and concentration used in our study. Unlike ejaculated sperm, most epididymal spermatozoa are immotile after collection, due to the presence of inhibitory factors in the epididymal fluid, maintaining these cells in a quiescent state (Turner and Reich, 1985). The replacement of this microenvironment for a flushing extender provided an energy substrate to epididymal sperm and possibly diluted the epididymal fluid, allowing the expression of sperm motility. Our results indicate that the supplementation of PTX accelerated this process through its effects, increasing the intracellular cAMP in epididymal sperm, and consequently, the number of motile sperm.

Equine semen is routinely submitted to centrifugation prior to cryopreservation to reduce the adverse effects of seminal plasma on post-thaw quality/motility (Moore et al., 2005). Likewise, the centrifugation of epididymal sperm can be also recommended for removal of epididymal fluid, once it suppresses the sperm movement (Usselman and Cone, 1983; Acott and Carr, 1984; Jeng et al., 1993; Das et al., 2010). The centrifuged samples, treated or nontreated, showed similarity in motion parameters (TM, VAP, ALH and RAP), confirming the hypothesis that epididymal sperm develops full motility when the epididymal fluid is removed and then exposed to the freezing extender. However, the effect of PTX remaining in epididymal sperm after centrifugation by the higher percentage of spermatozoa exhibiting progressive motility was observed in treated sperm in comparison to control group.

The PTX added prior to cryopreservation did not improve post-thaw motility or viability, corroborating previous reports (Esteves et al., 2007; Gil et al., 2010). Possibly the concentration used in our study was not sufficient to promote an effective response in the post-thaw spermatozoa to PF because they may require different concentrations for stimulation. The effect of PTX is evident when being added to cryopreserved stallion semen immediately after thawing, whereas the addition of $3.5 \mathrm{mM}$ PTX enhanced the post-thaw sperm motility (Gradil and Ball, 2000; Marques et al., 2002). Thus, PTX may be useful to activate spermatozoa that are in low metabolic post-thaw state (Gradil and Ball, 2000).

The cryopreservation process was detrimental to sperm motion characteristics and viability, irrespective of whether spermatozoa had been treated with PF before freezing or not, as previously reported (Esteves et al., 2007).

The ability of spermatozoa to undergo capacitation and acrosome reaction is considered to be the major event to achieve successful fertilization (Brucker and Lipford, 1995). During capacitation, the protein phosphorylation especially at tyrosine residues increases in sperm cell (Naz and Rajesh, 2004). It was reported that the treat- 
Table 1

Effect of pentoxifylline (PTX) on motility parameters of fresh, centrifuged and frozen-thawed cauda epididymal sperm ( $n=25$ stallions; 25 epididymis per treatment).

\begin{tabular}{|c|c|c|c|c|c|c|}
\hline & \multicolumn{2}{|l|}{ Fresh } & \multicolumn{2}{|l|}{ Centrifuged } & \multicolumn{2}{|c|}{ Frozen-thawed } \\
\hline & Control & PTX & Control & PTX & Control & PTX \\
\hline TM (\%) & $16.3 \pm 12.7^{\mathrm{A}}$ & $55.1 \pm 20.9^{\mathrm{a}, *}$ & $81.7 \pm 9.1^{\mathrm{B}}$ & $79.6 \pm 8.4^{\mathrm{b}}$ & $64.1 \pm 15.5^{\mathrm{C}}$ & $70.9 \pm 14.0^{\mathrm{a}}$ \\
\hline PM (\%) & $5.3 \pm 5.6^{A}$ & $20.8 \pm 10.9^{\mathrm{a},{ }^{*}}$ & $31.4 \pm 8.7^{\mathrm{B}}$ & $36.8 \pm 8.4^{\mathrm{b}, *}$ & $28.0 \pm 13.4^{\mathrm{B}}$ & $31.1 \pm 12.4^{b}$ \\
\hline $\operatorname{VAP}(\mu \mathrm{m} / \mathrm{s})$ & $76.6 \pm 8.6^{A}$ & $104.4 \pm 15.5^{\mathrm{a}, *}$ & $106.4 \pm 11.6^{\mathrm{B}}$ & $108.1 \pm 11.4^{\mathrm{a}}$ & $85.2 \pm 13.4^{\mathrm{A}}$ & $87.3 \pm 12.6^{\mathrm{b}}$ \\
\hline $\mathrm{ALH}(\mu \mathrm{m})$ & $6.9 \pm 2.3^{\mathrm{A}}$ & $7.6 \pm 1.7^{\mathrm{a}}$ & $7.56 \pm 0.62^{\mathrm{A}}$ & $7.37 \pm 0.68^{a}$ & $6.2 \pm 0.7^{\mathrm{B}}$ & $6.2 \pm 0.7^{b}$ \\
\hline $\operatorname{RAP}(\%)$ & $8.9 \pm 7.3^{\mathrm{A}}$ & $45.1 \pm 21.2^{\mathrm{a},{ }^{*}}$ & $71.4 \pm 12.5^{\mathrm{B}}$ & $75.8 \pm 11.5^{\mathrm{b}}$ & $42.3 \pm 20.4^{C}$ & $48.9 \pm 19.5^{a}$ \\
\hline PMI (\%) & $73.2 \pm 14.0^{\mathrm{A}}$ & $76.0 \pm 12.0^{\mathrm{a}}$ & & & $38.6 \pm 9.3^{\text {в }}$ & $38.5 \pm 10.3^{b}$ \\
\hline
\end{tabular}

TM, total motility; PM, progressive motility, VAP, average path velocity; ALH, amplitude of lateral head displacement; RAP, rapid sperm; PMI, plasma membrane integrity.

Significant differences between treatments within a given moment $(P<0.05)$

Different upper case letters indicate significant differences in control group considering all moments $(P<0.05)$.

Different lower case letters indicate significant differences in PTX group considering all moments $(P<0.05)$.
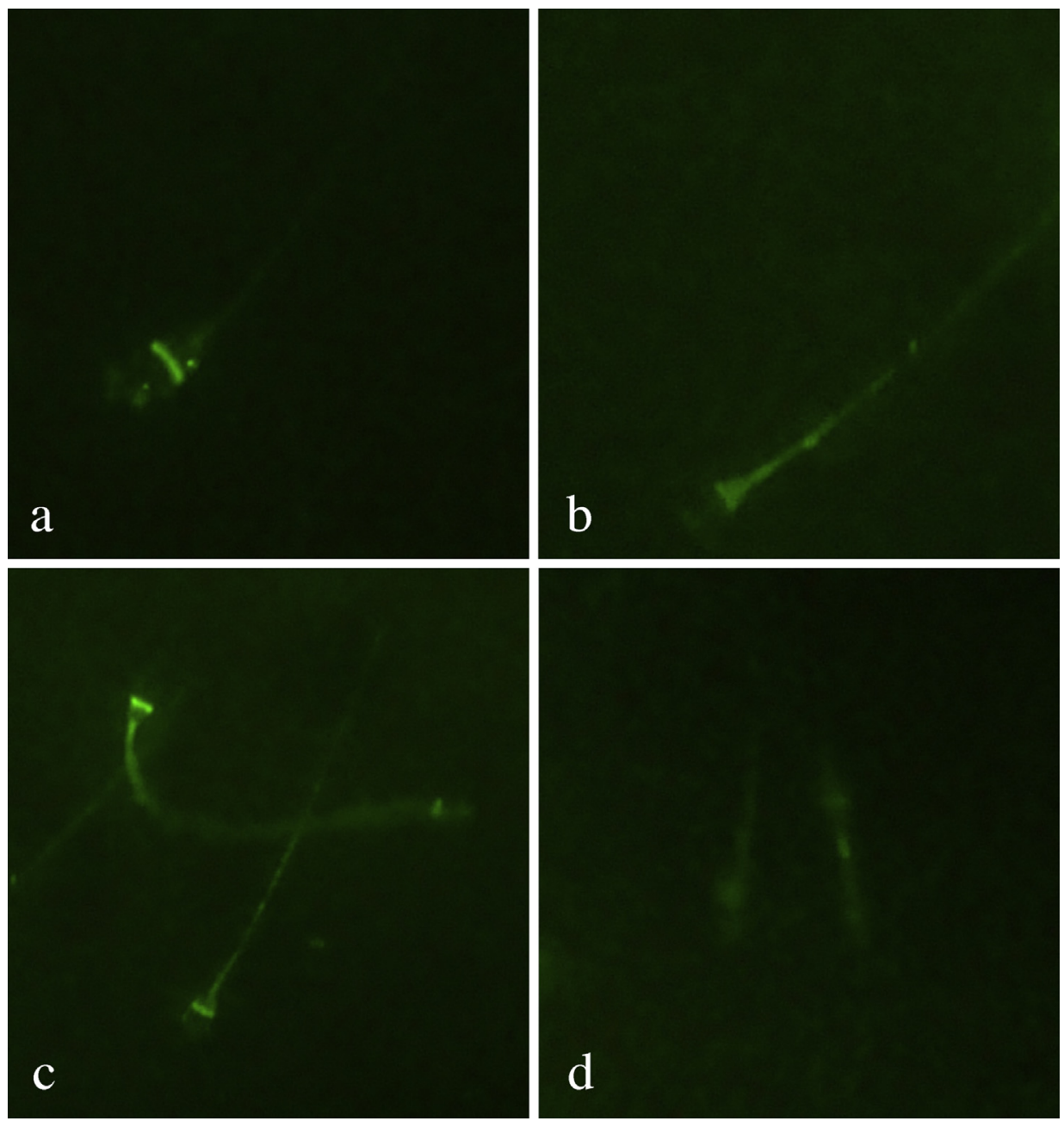

Fig. 1. Tyrosine phosphorylation immunofluorescence patterns of cryopreserved equine epididymal sperm. Four different patterns were identified: (a) equatorial band, (b) tail, (c) equatorial band with tail, and (d) none.

ment of fresh stallion-ejaculated spermatozoa with PTX (3.5 $\mathrm{mM}$ ) increase the proportion of live-capacitated spermatozoa (Ortgies et al., 2012) and the frozen ejaculated spermatozoa seems to be more susceptible to undergo tyrosine phosphorylation upon incubation under capac- itating conditions (Pommer et al., 2003). However, our results demonstrated that the prefreeze treatment of epididymal sperm with PTX did not affect the percentage of cells displaying tail-associated immunofluorescence of tyrosine residues, indicating that the concentration of PTX 


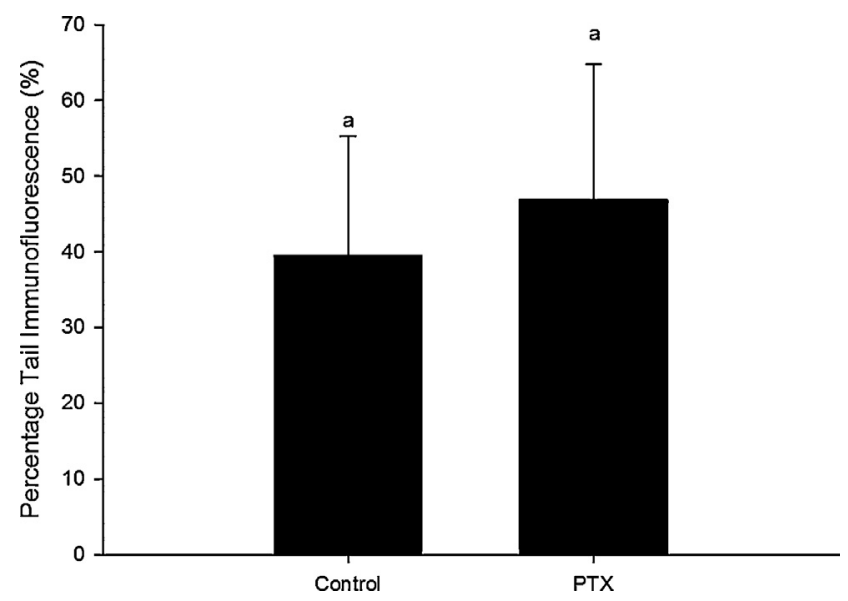

Fig. 2. Percentage sperm tail immunofluorescence of phosphorylated tyrosine residues in control and PTX group in cryopreserved stallion epididymal sperm. Values are expressed as mean percentage $\pm S D, n=25$. $P>0.05$.

used in this study did not prematurely capacitate stallion epididymal sperm.

In cattle, the bovine seminal plasma (BSP) proteins interact specifically with heparin and high density lipoproteins. These proteins bind to ejaculated sperm promoting the cholesterol and phospholipid efflux, which is an important step in the capacitation process (Manjunath and Therien, 2003). The horse seminal plasma (HSP-1, HSP-2, HSP-5 to HSP-8) are orthologs to BSP proteins and also showed heparin-binding properties (Topfer-Petersen et al., 2005), indicating a potential role in capacitation process. Moreover, the addition of heparin binding proteins of seminal plasma enhanced the capacitation response in frozen thawed stallion spermatozoa (Arangasamy, 2011). It is possible that the absence of seminal plasma proteins in epididymal sperm contribute to preservation of tyrosine proteins from phosphorylation, however, it is not possible to confirm this hypothesis since we did not evaluate ejaculated sperm.

Many studies have been conducted to find the optimal sperm concentration per insemination dose without compromising the stallion fertility (Morris, 2004; Samper and Plough, 2010; Govaere et al., 2014). The recommended minimum number of spermatozoa required for conventional artificial insemination in the mare is $200 \times 10^{6}$ progressively motile spermatozoa (Morris, 2004) and with less than $100 \times 10^{6}$ million spermatozoa will result in decreased pregnancy rates per cycle (Pace and Sullivan, 1975; Voss et al., 1979). In the present study, the insemination dose was reduced 8 times ( 800 million $v s 100$ million). Our results indicate that there were no significant differences in fertility rates reducing the sperm number per insemination dose of epididymal sperm recovered with a conventional skim milk based extender (C 800 vs $C$ $100)$. However, a trend toward significance $(P=0.07)$ was observed between these two groups. It is possible that the number of mares per insemination group was not sufficient to demonstrate the effect of insemination dose on conception rates. Therefore, based on this finding, probably the number of deposited sperm in C 100 was not sufficient to
Table 2

Effect of pentoxifylline (PTX) and insemination dose on fertility of cauda cryopreserved epididymal sperm.

\begin{tabular}{llll}
\hline Treatment & Insemination dose & Conception rate (\%) & $P$-value \\
\hline Control & $800 \times 10^{6}$ sperm & $11 / 16(68.7)^{\mathrm{a}}$ & - \\
Control & $100 \times 10^{6} \mathrm{sperm}$ & $5 / 16(31.5)^{\mathrm{a}}$ & 0.07 \\
PTX & $100 \times 10^{6} \mathrm{sperm}$ & $8 / 16(50)^{\mathrm{a}}$ & 0.47 \\
\hline
\end{tabular}

$P>0.05$.

$P$-value column compares control 100 and PTX with the control 800 group.

reach the fertilization site in the same manner as deposited a greater amount of spermatozoa (C 800).

In human reproduction, PTX is largely used in assisted reproductive technology (ART), as a stimulator of sperm motility and for its positive effects on fertilization rates (Yovich, 1993; Tardif et al., 2014). In horses, the effect of PTX on sperm has been only tested in in vitro assays (Goulart et al., 2004; Ortgies et al., 2012; Stephens et al., 2013). In the present study, the insemination dose of 100 million PTX pre-treated sperm did not improve the conception rates compared to control samples. Therefore, the hypothesis that PTX would significantly improve pregnancy rates in mares using the same insemination dose could not be supported.

The use of PTX in human fertilization in vitro (FIV) for severe male factor infertility provide satisfactory results (Tardif et al., 2014), though the time to reach the oocyte in this technique should be considered. In IVF procedures, a considerable number of spermatozoa are exposed to oocytes for 15-20 h (Huang et al., 2013) and for men with poor semen quality, sperm cells are stimulated prior to co-incubation (Henkel and Schill, 2003). The conventional artificial insemination requires time and viability of the sperm cell to reach the fertilization site in the oviduct (Morris, 2004; Giannoccaro et al., 2010). Moreover, previous studies reported that the motility-enhance effect of PTX appears to be transient (Gangrade, 2006).

Interestingly, the conception rate did not differ between the control group with a higher insemination dose (C 800 ) and the group with a lower insemination dose pretreated with PTX (PTX 100). Therefore, the pre-treatment 
of stallion epididymal sperm with PTX did not lead to premature capacitation, once similar fertility rates were observed between these two insemination groups. It is suggested that in spite of PTX did not have an effect on sperm motility patterns after cryopreservation, the effects of this substance are shown on the fertilizing capacity of the spermatozoa. Moreover, the modifications on sperm metabolism stimulated by PTX prior to freezing possibly occurred during the transport in the female reproductive tract.

Considering that the cryopreserved epididymal sperm represents a limited genetic reserve of a valuable stallion, reducing the insemination dose could be interesting, since greater amount of genetic material remains stored for future inseminations. The treatment of PTX in stallion sperm has shown positive results in in vitro assays (Goulart et al., 2004; Stephens et al., 2013) and although our findings indicates a positive effect in fertility, a low number of animals was used, resulting in low statistical power. Further research, possibly conducted on a larger number of animals, is required to evaluate better the results observed in this study and to elucidate the real effects of PTX on fertility of equine epididymal sperm.

\section{Conclusion}

The use of a flushing extender containing PTX enhanced the sperm motility after harvest. The PTX has no deleterious effect on sperm motility, viability and tyrosine phosphorylation of stallion epididymal sperm after cryopreservation. The limited number of doses recovered from the cauda epididymis may have its application maximized by conventional artificial insemination with $100 \times 10^{6}$ epididymal sperm recovered with a flushing extender containing pentoxifylline, to achieve acceptable conception rates.

\section{Conflict of interest}

None declared.

\section{Acknowledgement}

The São Paulo Research Foundation (FAPESP) for the financial support (grant number 08/52561-8 and 08/54287-0).

\section{References}

Arangasamy, A., 2011. Effect of stallion seminal plasma proteins on in-vitro capacitation of equine spermatozoa. Indian J. Anim. Sci. 80 (accessed 29.08.16)

http://epubs.icar.org.in/ejournal/index.php/IJAnS/article/view/2773.

Acott, T.S., Carr, D.W., 1984. Inhibition of bovine spermatozoa by caudal epididymal fluid: II. Interaction of $\mathrm{pH}$ and a quiescence factor. Biol. Reprod. 30, 926-935.

Brucker, C., Lipford, G.B., 1995. The human sperm acrosome reaction: physiology and regulatory mechanisms. Hum. Reprod. Update 1 51-62.

Bruemmer, J.E., 2006. Collection and freezing of epididymal stallion sperm. Vet. Clin. North Am. Equine Pract. 22, 677-682.

Carrel, D.T., Aston, K.I., 2013. Spermatogenesis: Methods and Protocols. Springer Science + Business Media, New York.

Cascieri, M., Amann, R.P., Hammerstedt, R.H., 1976. Adenine nucleotide changes at initiation of bull sperm motility. J. Biol. Chem. 254, 787-793
Cary, J.A., Madill, S., Farnsworth, K., Hayna, J.T., Duoos, L., Fahning, M.L., 2004. A comparison of electroejaculation and epididymal sperm collection techniques in stallions. Can. Vet. J. 45, 35-41.

Das, S., Saha, S., Majumder, G.S., Dungdung, S.R., 2010. Purification and characterization of a sperm motility inhibiting factor from caprine epididymal plasma. PLoS ONE 5, e12039.

Dell'aqua Jr., J.A., Papa, F.O., 2001. Efeito de diluentes e tempo de centrifugação, sobre os parâmetros espermáticos para congelação de sêmen equino, [Effect of extenders, intensity and time of centrifugation on sperm parameters of frozen equine semen]. Rev. Bras. Reprod. Anim. 25, 460-462 (in Portuguese)

Esteves, S.C., Spaine, D.M., Cedenho, A.P., 2007. Effects of pentoxifylline treatment before freezing on motility, viability and acrosome status of poor quality human spermatozoa cryopreserved by the liquid nitrogen vapor method. Braz. J. Med. Biol. Res. 40, 985-992.

Gadella, B.M., Rathi, R., Brouwers, J.F.H.M., Stout, T.A.E., Colenbrander, B., 2001. Capacitation and the acrosome reaction in equine sperm. Anim. Reprod. Sci. 68, 249-265.

Gangrade, B.K., 2006. Modulation of sperm motility-use of motility enhancing agents in artificial insemination. In: Allahbadia, G.N. (Ed.), Intrauterine Insemination. Jaypee Medical Publishers, New Delhi, pp. $149-157$.

Gil, M.A., Hernandez, M., Roca, J., Almiñana, C., Lucas, X., Cuello, C., Vazquez, J.M., Martínez, E.A., 2010. Pentoxifylline added to freezing or post-thaw extenders does not improve the survival or in vitro fertilising capacity of boar spermatozoa. Reproduction 139, 557-564.

Giannoccaro, A., Giovanni, M.L., Filannino, A., Pizzi, F., Nicassio, M. Dell'Aquila, M.H., Minervini, F., 2010. Assessment of viability, chromatin structure stability, mitochondrial function and motility of stallion fresh sperm by using objective methodologies. JCAB 4, 34-41.

Goulart, H.M., Silva, A.E.D.F., McManus, C., Papa, F.O., 2004. Efeitos da pentoxifilina sobre a viabilidade in vitro dos espermatozóides de eqüinos, após o resfriamento a $5^{\circ} \mathrm{C}$, [Effects of pentoxifylline on the in vitro viability of equine spermatozoids, after cooling at $5^{\circ}$. Rev. Bras. Zootec. 33, 112-122 (in Portuguese).

Govaere, J.L., Hoogewijs, M.K., De Schauwer, C., De Vliegher, S., Van Soom, A., Duchateau, L., de Kruif, A., 2014. Effect of artificial insemination protocol and dose of frozen/thawed stallion semen on pregnancy results in mares. Reprod. Domest. Anim. 49, 487-491.

Gradil, C.M., Ball, B.A., 2000. The use of pentoxifylline to improve motility of cryopreserved equine spermatozoa. Theriogenology 54 , 1041-1047.

Guasti, P.N., Monteiro, G.A., Maziero, R.R.D., Martin, I., Avanzi, B.R., DellAqua Jr., J.A., Papa, F.O., 2013. Effects of pentoxifylline on equine epididymal sperm. J. Equine Vet. Sci. 33, 1153-1156.

Hassanpour, H., Mirshokraei, P., Tajik, P., Haghparast, A., 2010. In vitro effects of pentoxifylline on kinematics parameters, capacitation, and acrosome reaction of ram epididymal sperm. Comp. Clin. Pathol. 19, 377-381.

Harrison, R.A.P., Vickers, S.E., 1990. Use of fluorescent probes to assess membrane integrity in mammalian spermatozoa. J. Reprod. Fertil. 88, 343-352.

Henkel, R.R., Schill, W.B., 2003. Sperm preparation for ART. Reprod. Biol. Endocrinol. 1, 108

Huang, Z., Li, J., Wang, L., Yan, J., Shi, Y., Li, S., 2013. Brief co-incubation of sperm and oocytes for in vitro fertilization techniques. Cochrane Database Syst. Rev. 4, Art. No.: CD009391.

Jeng, H., Liu, K.M., Chang, W.C., 1993. Purification and characterization of reversible sperm motility inhibitors from porcine seminal plasma. Biochem. Biophys. Res. Comm. 191, 435-440.

Kovacic, B., Vlaisavljevic, V., Reljic, M., 2006. Clinical use of pentoxifylline for activation of immotile testicular sperm before ICSI in patients with azoospermia. J. Androl. 27, 45-52.

Lewis, S.E., McKinney, K.A., Thompson, W., 1994. Influence of pentoxifylline on human sperm motility in asthenozoospermic individuals using computer-assisted analysis. Arch. Androl. 32, 175-183.

Luconi, M., Porazzi, I., Ferruzzi, P., Marchiani, S., Forti, G., Baldi, E., 2005. Tyrosine phosphorylation of the a kinase anchoring protein 3 (AKAP3) and soluble adenylate cyclase are involved in the increase of human sperm motility by bicarbonate. Biol. Reprod. 72, 22-32.

Manjunath, P., Therien, I., 2003. Role of seminal plasma phospholipid-binding proteins in sperm membrane lipid modification that occurs during capacitation. J. Reprod. Immunol. 53, 109-119.

Marques, A., Arruda, R.P., Celeghini, E.C.C., Gobesso, A.A.O., Neves Neto, J.R., 2002. Effects of ascobic acid and pentoxifylline on equine 
cryopreserved semen submitted to in vitro incubation. Theriogenology 58, 257-260.

Monteiro, G.A., Guasti, P.N., Rocha, A.S., Martin, I., Sancler-Silva, Y.F.R., Dell'Aqua Jr., J.A., Papa, F.O., 2013. Effect of storage time and temperature of equine epididymis on the viability, motion parameters, and freezability of epididymal sperm. J. Equine Vet. Sci. 33, 169-173.

Moore, A.I., Squires, E.L., Graham, J.K., 2005. Effect of seminal plasma on the cryopreservation of equine spermatozoa. Theriogenology 63, 2372-2381.

Morton, B.E., Sagadraca, R., Fraser, C., 1978. Sperm motility within the mammalian epididymis: species variation and correlation with free calcium levels in epididymal plasma. Fertil. Steril. 29, 695-698.

Morris, L., Tiplady, C., Allen, W.R., 2002. The in vivo fertility of cauda epididymal spermatozoa in the horse. Theriogenology 58, 643-646.

Morris, L., 2004. Low dose insemination in the mare: an update. Anim. Reprod. Sci. 82-83, 625-632.

Nassar, A., Morshedi, M., Mahony, M., Srisombut, C., Lin, M.H., Oehninger, S., 1999. Pentoxifylline stimulates various sperm motion parameters and cervical mucus penetrability in patients with asthenozoospermia. Andrologia 31, 9-15.

Naz, R.K., Rajesh, P.B., 2004. Role of tyrosine phosphorylation in sperm capacitation/acrosome reaction. Reprod. Biol. Endocrinol. 2, 75.

Ortgies, F., Klewitz, J., Gorgens, A., Martinsson, G., Sieme, H., 2012. Effect of procaine, pentoxifylline and trolox on capacitation and hyperactivation of stallion spermatozoa. Andrologia 44, 130-138.

Pace, M.M., Sullivan, J.J., 1975. Effect of timing of insemination, numbers of spermatozoa and extender components on the pregnancy rate in mares inseminated with frozen stallion semen. J. Reprod. Fertil. Suppl. 23, 115-121.

Papa, F.O., Melo, C.M., Fioratti, E., DellaAqua, J.A., Zahn, F.S., Alavarenga, M.A., 2008. Freezing of stallion epididymal sperm. Anim. Reprod. Sci. 107, 293-301.

Pommer, A.C., Rutilland, J., Meyers, S.A., 2003. Phosphorylation of protein tyrosine residues in fresh and cryopreserved stallion spermatozoa under capacitating conditions. Biol. Reprod. 68, 1208-1214.

Rashidi, I., Movahedin, M., Tiraihi, T., 2004. The effects of pentoxifylline on mouse epididymal sperm parameters, fertilization and cleavage rates after short time preservation. Iran J. Reprod. Med. 2, 51-57.

Samper, J.C., Plough, T., 2010. Techniques for the insemination of low doses of stallion sperm. Reprod. Domest. Anim. 45, 35-39.
Stachecki, J.J., Ginsburg, K.A., Armant, D.R., 1994. Stimulation of cryopreserved epididymal spermatozoa of the domestic cat using the motility stimulants caffeine, pentoxifylline, and 2'-deoxyadenosine. J. Androl. 15, 157-164.

Stawicky, R.J., McDonnell, S.M., Giquere, S., Turner, R.M., 2016. Pregnancy outcomes using stallion epididymal sperm stored at $5{ }^{\circ} \mathrm{C}$ for 24 or 48 hours before harvest. Theriogenology 85, 698-702.

Stephens, T.D., Brooks, R.M., Carrington, J.L., Cheng, L., Carrington, A.C. Porr, C.A., Splan, R.K., 2013. Effects of pentoxifylline, caffeine, and taurine on post-thaw motility and longevity of equine frozen semen. J. Equine Vet. Sci. 33, 615-621.

Tardif, S., Madamidola, O.A., Brown, S.G., Frame, L., Lefièvre, L., Wyatt, P.G., Barratt, C.R.L., Da Silva, S.J.M., 2014. Clinically relevant enhancement of human sperm motility using compounds with reported phosphodiesterase inhibitor activity. Hum. Reprod. 29, $2123-2135$.

Tash, J.S., 1990. Role of cAMP, calcium and protein phosphorylation in sperm motility. In: Gagnon, C. (Ed.), Controls of Sperm Motility: Biological and Clinical Aspects. CRC Press, Boca Raton, pp. 229-241.

Terriou, P., Giorgetti, H.C., Spach, J.L., Salzmann, J., Urrutia, V., Roulier, R. 2000. Pentoxifylline initiates motility in spontaneously immotile epididymal and testicular spermatozoa and allows normal fertilization, pregnancy, and birth after intracytoplasmic sperm injection. J. Assist. Reprod. Genet. 17, 194-199.

Topfer-Petersen, E., Ekhlasi-Hundrieser, M., Kirchhoff, C., Leeb, T., Sieme, $\mathrm{H} ., 2005$. The role of stallion seminal proteins in fertilization. Anim. Reprod. Sci. 89, 159-170.

Turner, T.T., Reich, G.W., 1985. Cauda epididymidal sperm motility: a comparison among five species. Biol. Reprod. 32, 120-128.

Usselman, M.C., Cone, R.A., 1983. Rat sperm are mechanically immobilized in the caudal epididymis by "immobilin," a high molecular weight glycoprotein. Biol. Reprod. 29, 1241-1253.

Voss, J.L., Wallace, R.A., Squires, E.L., Pickett, B.W., Shideler, R.K., 1979. Effects of synchronisation and frequency of insemination on fertility. J. Reprod. Fertil. Suppl. 27, 257-261.

Wong, P.Y.D., Lee, W.M., Tsang, A.Y.F., Fu, W.O., Chan, Q.Q., 1983. Lack of an effect of gossypol on the epididymis of the rat. Contraception 27, 391-400.

Yanagimachi, R., 1994. Mammalian fertilization. In: Knobil, E., Neill, J.D. (Eds.), The Physiology of Reproduction. Raven Press, New York, pp. 189-317

Yovich, J.L., 1993. Pentoxifylline: actions and applications in assisted reproduction. Hum. Reprod. 8, 1786-1791. 